Microbes and Health

ISSN: 2226-0153 (Print) 2305-3542 (Online)

http://journal.bsvmph.org/

Microbes and Health, December 2012, 1(2): 62-64 DOI: $10.3329 / \mathrm{mh} . \mathrm{v} 1 \mathrm{i} 2.14092$

\title{
Isolation and Characterization of Salmonella Serovars from Buffaloes in Mymensingh, Bangladesh
}

\author{
Nahid Rahman*, Md. Shahidur Rahman Khan, Md. Mansurul Amin, Mahbubul Pratik Siddique, Jayedul Hassan and Kohinoor \\ Parvin
}

Department of Microbiology and Hygiene, Faculty of Veterinary Science, Bangladesh Agricultural University, Mymensingh-2202, Bangladesh.

*Corresponding author's e-mail: nahid.rahman18@yahoo.com

[Received: 29 November 2012, Revised: 17 December 2012, Accepted: 20 December 2012]

\section{A B S T R A C T}

An investigation was carried out focusing the isolation and characterization of Salmonella serovars from buffaloes of some selected areas of Mymensingh district of Bangladesh. The objectives was to isolate and identify Salmonella serovars from diarrheic and apparently healthy buffaloes and to characterize the isolates by cultural and biochemical characteristics, serological tests and antibiotic sensitivity analysis. A total of 38 samples comprising rectal swabs and faeces were collected from 38 buffaloes originating from 3 selected areas of Mymensingh. Out of these 38 samples, $8(20.63 \%)$ were found to be positive for Salmonella spp. All isolates fermented dextrose, maltose and mannitol with production of acid and gas but did not ferment sucrose and lactose. On the other hand, these isolates showed Indole and VogesProskaure test negative, Methyl-Red test positive. All these isolates subjected to rapid plate agglutination test with polyvalent "O" ( poly 'O') and polyvalent " $\mathrm{H}$ " ( poly 'H') antisera where positive agglutination were observed. All isolates were highly sensitive to ciprofloxacin, moderately sensitive to co-trimoxazole, gentamycin, tetracycline and less sensitive to erythromycin and resistant to furazolidone.

Keywords: Isolation, Characterization, Salmonella, Serovars, Buffalo, Mymensingh

(C) 2012 Microbes and Health. All rights reserved

\section{Introduction}

Salmonellosis is a disease condition caused by a wide variety of Salmonella spp. in various hosts including humans, cattle, sheep, goats, pigs, chickens, ducks and buffaloes (OIE, 2006) which remains as a serious public health problem throughout the world. Salmonellosis is manifested clinically in all hosts by one of three major syndromes: per-acute systemic infection, acute enteritis or chronic enteritis (Merchant and Packer, 1967). Among domesticated animals, buffaloes constitute one of the important reservoirs of Salmonella and are susceptible to disease caused by a wide variety of serotypes. Salmonella infection in buffalo occurs in all ages and is responsible for a considerable loss of buffalo calves, (Arruda et al., 2004). This infection may be a major problem in meat producing and buffalo rearing industries and areas where this will surely impair the fattiness and sound health of buffalo and give the poor quality and quantity of meat which leads to poor market value (Arruda et al., 2004). On the other hand, Salmonella organisms were isolated from chickens (Begum, 1992), goats (Rahman, 2006), Cattle (Islam 2007), Sheep (Karim, 2007), ruminants (Rahman, 2007) in the Department of Microbiology and Hygiene, Faculty of veterinary Science (FVS), Bangladesh Agricultural University (BAU), Mymensingh. Further details on Salmonella serovars infecting Buffaloes in Bangladesh including the antibacterial sensitivity pattern deemed important to design proper control measures. Present study was designed to isolate and characterize Salmonella serovars using cultural, morphological, biochemical and serological examination to know the prevalence of Salmonellosis in buffaloes of Bangladesh as well as to reveal the antibiotic

To cite this article: Rahman N, MSR Khan, MM Amin, MP Siddique, J Hassan and $\mathrm{K}$ Parvin, 2012. Isolation and Characterization of Salmonella Serovars from Buffaloes in Mymensingh. Microbes Health, 1(2): 62-64. sensitivity and resistance pattern of the isolates.

\section{Materials and Methods}

Collection of samples

A total of 38 field samples comprising rectal swab from apparently healthy and diarrheic buffaloes, reared at BAU dairy farm, Trishal and Boyra area, Mymensingh, were collected under aseptic condition and carried out to the laboratory using Nutrient broth (NB).

\section{Isolation and characterization}

The collected samples from apparently healthy and diarrheic buffaloes were inoculated to Nutrient agar (NA), SalmonellaShigella agar (SS), Brilliant green agar (BG), MacConkey agar (MC) and Eosin methylene blue agar (EMB). Petridishes were incubated at $37^{\circ} \mathrm{C}$ for $24-48$ hours and growing colonies were examined with Gram's staining method (Merchant and Packer, 1967) and motility test with hanging drop slide (Cowan, 1974).Biochemical characterization of the isolates were performed with Sugar fermentation test, Methyl Red test(MR) and Voges-Proskaucer test (V-P) (Cheesbrough, 1985).

\section{Serological test}

Salmonella agglutinating antiserum poly "O" and poly "H" (S \& E reagents Lab, Bangkok, Thailand) was used to perform the serotyping of the isolated Salmonella spp. The macroscopic slide agglutination tests were performed. A single isolated colony from SS agar was emulsified with physiological saline solution. A single drop of thick bacterial suspension was placed on a glass slide and a drop of polyvalent antiserum was added. The slide was gently rotated to mix the fluid thoroughly. These cultures which agglutinated within one to two minutes were selected as positive for Salmonella and subjected to agglutination test with 
Salmonella agglutinating antiserum (poly "H"). According to manufacturer's direction, it was noted that poly "O" antiserum gives positive agglutination reaction with any serovars for preliminary screening of Salmonellae and poly " $\mathrm{H}$ " antiserum gives specific agglutination reaction for motile Salmonella spp. (Buxton and Fraser, 1977).

\section{Antibiotic sensitivity test}

Susceptibility of the isolated Salmonellae to different antibacterial agents was performed following the disc diffusion method (Bauer et al, 1966) to determine the drug sensitivity pattern. Sensitivity to antibiotic was mostly determined on Nutrient agar with tetracycline, gentamycin, co-trimoxazole, furozolidone, erythromycin, ciprofloxacin. The inhibitory effect of the antibacterials to the growth of the culture was recorded (Bauer et al., 1966)

\section{Result}

Cultural and biochemical characterization of Salmonellae

All the isolates Salmonellae from three different areas showed characteristics colony morphology in NB agar, SS agar, MC agar, TSI agar, BG agar media. The isolates were Gram negative, small rod shaped, single or paired in arrangement and motile. In sugar fermentation test, all isolated Salmonellae fermented dextrose, maltose and mannitol and produced acid and gas but did not ferment sucrose and lactose. In addition, all the isolates were found positive for MR test and negative to Indole test and V-P test (Cheesbrough, 1985).

Table 1. Cultural, morphological and biochemical characteristics of the isolated Salmonellae from buffaloes

\begin{tabular}{|c|c|c|c|c|c|c|c|}
\hline \multirow[t]{2}{*}{ No. of samples (n) } & \multicolumn{2}{|c|}{ Cultural examination } & \multicolumn{2}{|c|}{ Biochemical examination } & \multicolumn{2}{|c|}{ Gram staining examination } & \multirow[t]{2}{*}{ Prevalence } \\
\hline & $\begin{array}{l}\text { Positive for } \\
\text { Salmonella }\end{array}$ & $\begin{array}{l}\text { Negative for } \\
\text { Salmonella }\end{array}$ & $\begin{array}{l}\text { Positive for } \\
\text { Salmonella }\end{array}$ & $\begin{array}{l}\text { Negative for } \\
\text { Salmonella }\end{array}$ & Single & Paired & \\
\hline BAU dairy farm (12) & 3 & 9 & 3 & 9 & 2 & 1 & $25 \%$ \\
\hline Trishal(14) & 4 & 10 & 4 & 10 & 2 & 2 & $28.57 \%$ \\
\hline Boyra (12) & 1 & 11 & 1 & 11 & - & 1 & $8.33 \%$ \\
\hline Total (38) & 8 & 30 & 8 & 30 & 4 & 4 & $21.05 \%$ \\
\hline
\end{tabular}

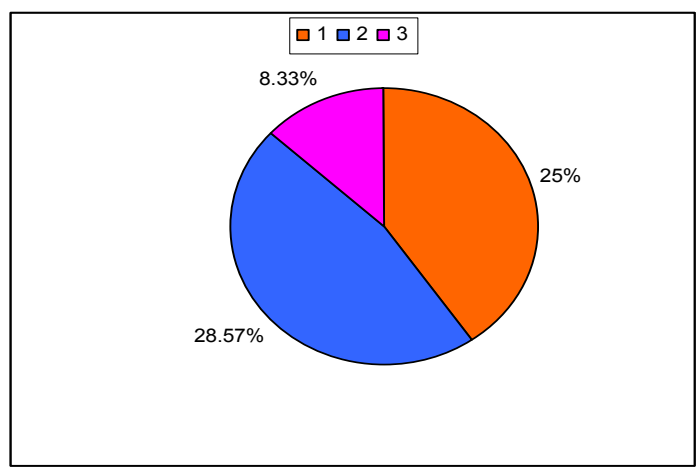

Fig. 1. Pie diagrammatic presentation of overall prevalence (as shown in Table 1) of buffalo origin Salmonella in three different regions. Legends: $1=\mathrm{BAU}$ dairy farm, $2=$ Trishal, $3=$ Boyra, Mymensingh

Serological characteristics of isolated Salmonellae Out of 38 samples, 8 samples were isolated and all isolates were positive to agglutination tests confirming Salmonella spp.

Antibiotic sensitivity test of isolated Salmonellae

The isolated Salmonellae from all three areas were highly sensitive to Ciprofloxacin, gentamycin; moderately sensitive to Co-trimoxazole, tetracycline, gentamyin. They are less sensitive to erythromycin, tetracycline and nearly resistant to furozolidone.

\section{Discussion}

The isolated Salmonella serovars produced opaque, translucent, colorless and smooth, round colonies on SS agar; pale colorless smooth, transparent, raised colonies on MC agar, pale pink color colonies in BG agar (Buxton and Fraser, 1977; Merchant and Packer, 1967 \& Shaffer et al., 1964). In Gram staining, the isolated Salmonellae showed Gram negative, small rod shaped,

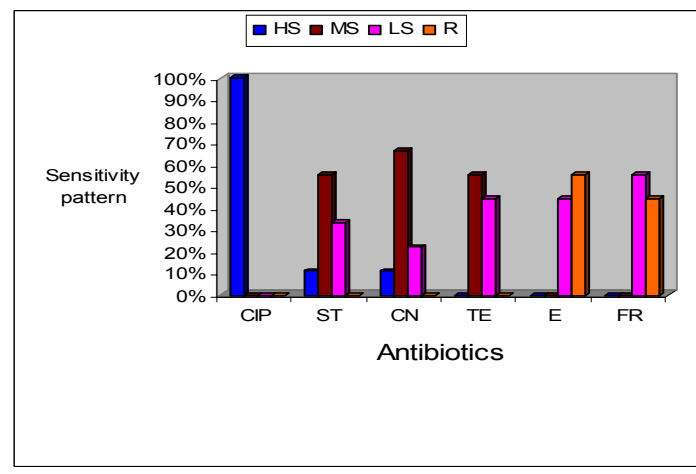

Fig. 2. Diagrammatic presentation of Antibiotic Sensitivity and Resistance pattern of buffalo Salmonellae isolates $(\mathrm{CIP}=$ Ciprofloxacin, $\mathrm{ST}=$ Co-trimoxazole, $\mathrm{CN}=$ Gentamycin, $\mathrm{TE}=$ Tetracyclin, E= Erythromycin, FR= Furozolidone, HS = highly sensitive, $\mathrm{MS}=$ Moderately sensitive, $\mathrm{LS}=$ Less sensitive, $\mathrm{R}=$ Resistant)

single or paired in arrangement which was supported by other researchers (Gene, 2002, Jones et al., 1997 and Freeman, 1985). In motility test, all isolates of buffalo have shown swinging movement with forward movement (Buxton and Fraser, 1977 \& Merchant and Packer, 1967). All the isolated Salmonellae fermented dextrose, maltose and mannitol and produced acid and gas but did not ferment sucrose and lactose (Buxton and Fraser, 1977). All the isolated were positives to MR test and negative to Indole test. Slide agglutination test was performed with commercially available agglutinating polyvalent antisera. The isolates gave positive result to agglutination test with both poly "O" and poly "H" antisera which indicated that the isolates were of Salmonella spp. ELISA can also be done but expensive and gives non-specific reaction and time consuming (Begum, 2005) whereas slide agglutination test is very simple, sensitive (Avakian et al., 1988).

The study also showed that the isolated Salmonellae were highly sensitive to Ciprofloxacin, gentamycin; moderately sensitive to Co-trimoxazole, tetracycline, gentamyin. They were less 
sensitive to erythromycin, tetracycline and nearly resistant to furozolidone. This finding is similar to the result of Chugh and Suheir, 1983; Banani et al., 2003; Zhang et al., 2006 and Kobayashi et al., 2007.

\section{Conclusion}

The overall prevalence of Salmonella spp. was $21.05 \%$ from buffalo fecal samples as detected by cultural, morphological and biochemical examination and by slide agglutination test. This method may used for the rapid detection of Salmonella in field cases in buffaloes. Ciprofloxacin, co-trimoxazole, gentamycin appears to be the choice of drug from the list of antibacterial agents we tested. The antibacterial resistance observed here in the isolated Salmonellae might be due to indiscriminate use of these antibacterial agents in field condition in study areas and/or rapid chromosomal mutation and presence of specific plasmid DNA.

\section{Acknowlegements}

We thank Dr. Md. Tanvir Rahman, Associate Professor, Department of Microbiology and Hygiene, Bangladesh Agricultural University, Mymensingh-2202, Bangladesh for his critical corrections and suggestions on the manuscript.

\section{References}

Arruda S.G.B, T.M.B Biscontini and T.L.M Stamford 2004. Microbiological characterization of buffalo subjected to different forms of management. Hygiene Alimentar. 18:58-62.

Avakian A.P, S.H Kleven. and J.R Glisson, 1988. Evalution of the specifity and sensitivity of two commercial enzyme linked immunosorbent serum plate agglutination test and haemagglutination inhibition antibiotics formed in response to Salmonella spp. Avian Dis.32:262-272.

Banani M, S.A Pourbakhsh, P Khaki and G.H Nikookhesal, 2003. Serotyping and drug sensitivity of Salmonella isolates from buffaloes submitted to Razi Institute. Pajouhesh-vasadandegi-in-Animal-Scienes. 59:92-96.

Bauer AW, WMM Kirdy, JC Sheris and M Truck, 1966. Antibiotic susceptibility testing by a standardized sin- gle disk method. Am J Clin Path, 145: 225-230.

Begum F, 1992. Characterization of Salmonella isolated from apparently healthy and diarrheice ducks. M.S. thesis, Department of Microbiology and Hygiene, Bangladesh Agricultural University, Mymensingh.

Begum F, 2005. A $37.81 \mathrm{kDa}$ protein reacting with sera obtained from Salmonella spp infected buffalo in Salmonella serovars. Ph.D. thesis. Submitted to the United Graduate School, Tokyo University of Agriculture and Technology, Tokyo, Japan

Buxton A and G Fraser, 1977. Animal Microbiology. Vol.1. Blackwell Scientific Publications, Oxford, London, Edinburg, Melbourne. 85-86,99.

Cheesbrough M. 1985. Medical laboratory manual for tropical countries. Vol. 2. Microbiology, pp. 400-480.

Chugh T.D. and A Suheir, 1983. Drug resistance among Salmonellae in Kuwait. Trop Geograph. Med. 35:37-41.

Cowan S.T, 1974. Cown abd Steel's Manual for the Identification of Medical bacteria. $2^{\text {nd }}$ edn, Cambridge University press, Cambridge, UK.

Freeman, B.A 1985. Burrows textbook of microbiology. 22"d edn. W. B. Saunders Company, Philadelphia, London, Toronto, Mexici City, Rio de Janerio, Sydney, Tokyo, 464-472.

Gene, O. 2002. The isolation and identification and serotyping of Salmonella isolated from domestic poultry in Kars district. Kafkas Univarsikesi Veteriner Fakultesi, Dergisi. 8: 23-30.

Islam, M.M 2007. Characterization of Salmonella isolated from apparently healthy and diarrheice calves. M.S. manuscript. Department of Microbiology and Hygiene, Bangladesh Agricultural University, Mymensingh.

Jones, T.C, R.D Huntand and N.W King, 1997. Veterinary pathology. 6th edu. Williams and Wilkins Co, Baltmore, USA.

Karim, R.M 2007. Investigation of sheep Salmonellosis in and around Bangladesh Agricultural UniversityCampus. M.S. thesis, Department of Microbiology and Hygiene, Bangladesh Agricultural University, Mymensingh.

Kobayashi II, M Kanazaki, Y Shimizu, J Nakajima, M.M Khatun, E Hata. and M Kubo, 2007. Salmonella isolates from rectal swabs and feaces of animals in the immediate environment of "Tokyo Bay. J. Vet. Med. Sci. 69:309-IL

Merchant A and R.A Packer 1967. Veterinary bacteriology and virology, 7th edn. The Iowa University Press, Ames, Iowa, USA, pp. 286-306.

Office International Des Epizooties (OIE), 2006 http://www.oie.int/chapterX.4.Salmonellosis

Rahman, M.S 2006. Investigation on animal Salmonella through retrospective case study and the application of antibiogram with Salmonella. M.S. thesis. Department of Microbiology and Hygiene, Bangladesh Agricultural University, Mymensingh.

Rahman, M.M 2007. Isolation and identification of Salmonella and Escherichia coli from river water, pond water, tap water, tube well water and poultry feed. M.S. Thesis, Department of Microbiology and Hygiene, Faculty of Veterinary Science, Bangladesh Agricultural University, Mymensingh.

Shaffer M.F, J.F Bridges, D.I Clemmerand and K.C Pontoppidan, 1964. Susceptibility of buffaloes to experimental injection with Salmonella typhosa. Am. Jour. Hyg. 80: 377-387.

Zhang Q, O Sahin, P.F McDermott and S Payot, 2006. Fitness of antimicrobial-resistant Campylobacter and Salmonella. Microbes and Infection. 8:1972-8. 